\title{
Prostate-Specific Antigen testing in men between 40 and 70 years in Brazil: database from a check-up program
}

\author{
João Paulo Zambonn ${ }^{1,2,3}$, Fernando G. Almeida1', Raquel Dilguerian 0. Conceição², Viviane Arevalo \\ Tabone², Nea Miwa Kashiwagi², Christina L. Ross², José Antônio Maluf de Carvalho² \\ ${ }^{1}$ Department of Urology, Universidade Federal de Sao Paulo, SP, Brazil; ${ }^{2}$ Hospital Israelita Albert Einstein, \\ SP, Brazil; ${ }^{3}$ Wake Forest University, Winston-Salem, North Carolina, USA
}

\begin{abstract}
Objectives: To evaluate the PSA in a large population of Brazilian men undergone to check up, and correlate the PSA cutoffs with prostate size and urinary symptoms.

Materials and Methods: This is a cross sectional study performed with men between 40 and 70 years undergone to check-up. All men were undergone to urological evaluation, digital rectal examination, prostate-specific antigen, and ultrasonography The exclusion criteria were men who used testosterone in the last six months, or who were using 5 alpha-reductase inhibitors.

Results: A total of 5015 men with an average age of 49.0 years completed the study. Most men were white and asymptomatic. The PSA in the three different aging groups were $0.9 \pm 0.7 \mathrm{ng} / \mathrm{dL}$ for men between 40 and $50 ; 1.2 \pm 0.5 \mathrm{ng} / \mathrm{dL}$ for men between 50 and 60 ; and $1.7 \pm 1.5 \mathrm{ng} / \mathrm{dL}$ for men greater than 60 years $(\mathrm{p}=0.001)$. A total of $192 \mathrm{men}$ had PSA between 2.5 and $4 \mathrm{ng} / \mathrm{ml}$. From these men 130 were undergone to prostate biopsy. The predictive positive value of biopsy was 25\% (32/130). In the same way, 100 patients had PSA $>4 \mathrm{ng} / \mathrm{mL}$. From these men, 80 were undergone to prostate biopsy. In this group, the predictive positive value of biopsy was 40\% (32/100). The Gleason score was 6 in 19 men (60\%), 7 in 10 men (31\%) and 8 in 3 men (9\%).

Conclusions: The PSA level of Brazilian men undergone to check up was low. There was a positive correlation with aging, IPSS and prostate size.
\end{abstract}

\section{ARTICLE INFO}

\section{Key words:}

screening; prostate cancer; PSA;

IPSS; check up; prostate size

Int Braz J Urol. 2014; 40: 745-52

Submitted for publication:

October 28, 2013

Accepted after revision:

April 06, 2014

\section{INTRODUCTION}

Prostate cancer is the second most commonly diagnosed type of cancer in the world, and the sixth leading cause of death in men worldwide. On a global level the incidence and prevalence of prostate cancer varies more than 25-fold worldwide, with highest incidence in developed countries of North America, Europe and Australia, and lower incidence rates in underdeveloped countries. These differences may occur due to the increased levels of screening and testing for prostate cancer in these developed countries (1-3).

The primary goal of prostate cancer screening is to reduce deaths due to prostate cancer, thus increasing life span. An additional important outcome of this type of screening would be a reduction in the development of symptomatic metastatic disease. Contemporary recommendations for prostate cancer screening incorporate the measurement of serum prostate-specific antigen (PSA) levels associated with other methods of detection 
such as digital rectal examination and/or ultrasonography $(4,5)$.

With regards to screening accuracy, studies have demonstrated that a PSA cutoff of $4.0 \mu \mathrm{g} / \mathrm{L}$ can detect many cases of prostate cancer; however, some will be missed. Using a lower cutoff level detects more cases, but at the cost of falsely labeling more men as potentially having cancer. Whether, for instance, the PSA cutoff is decreased to $2.5 \mu \mathrm{g} / \mathrm{dL}$, more than double the number of men aged 40 to 69 years will be labeled as a false positive $(6,7)$. These false positive results are associated with negative psychological effects. In addition, men who have a false positive result are more likely to have additional testing, including one or more biopsies in the year following diagnosis, as compared with those who have a negative test result. Almost one third of these biopsied patients experience pain, fever, bleeding, infection, transient urinary difficulties, and $1 \%$ even require hospitalization $(8,9)$.

Theoretically, the early detection of prostate cancer in younger asymptomatic men could significantly reduce the mortality rates; however, in most cases those tumors will not progress or will progress so slowly that they would have remained asymptomatic during the lifetime of the patient. The term overdiagnosis is used to describe this situation. Lower PSA cutoffs and screening tests performed in younger men increase the probability of overdiagnosis (10). There is a high propensity for physicians to treat most cases of screen-detected cancer, given our current inability to distinguish indolent from aggressive tumors. Thus, many patients are being subjected to the harmful effects of prostate cancer treatment that will never become symptomatic $(11,12)$.

The primary objective of this study was to evaluate the PSA levels in a large population of young Brazilian men submitted to a health check up program. The second objective was to correlate the different PSA cutoffs with aging, prostate size, and urinary symptoms.

\section{MATERIAL AND METHODS}

Data from the present study were collected from the check-up program performed between January and December 2011 at a private hospital in Sao Paulo, Brazil. This study was approved by local ethics committee and all patients signed out an informed consent.

During the examination, a multidisciplinary team composed of general clinicians, urologists, ophthalmologists, dermatologists, nurses, nutritionists and physiotherapists evaluated the patients.

Men between the ages of 40 and 70 years old were submitted to a urological evaluation, which consisted of a clinical history, International Prostate Symptom Score (IPSS) (13), digital rectal examination (DRE), prostate-specific antigen (PSA), urinalysis, and abdominal ultrasonography. The prostate size was measured by abdominal ultrasonography despite the limitations of this method. The digital rectal examination was performed in every patient over the age of $45 \mathrm{and} /$ or over the age of 40 for those with a history of prostate cancer in their family, or whose race was African-American.

The inclusion criteria were men between 40 and 70 years old, without previous history of prostate and/or bladder cancer. The exclusion criteria were any type of bladder or prostate surgery, men who used testosterone in the last six months, or those who were using 5 alpha-reductase inhibitors.

All patients received an orientation (which was sent by email or mail postal service) two weeks before the check-up. Blood was drawn before beginning the examination. With regards to PSA testing, men were instructed to avoid sexual activity $72 \mathrm{~h}$ before the exam. In cases where the PSA test was greater than $4.0 \mathrm{ng} / \mathrm{dL}$, the blood draw was repeated to confirm the result. The PSA dosage was carried out using an ultra-sensible PSA assay with a detection limit of $0.003 \mathrm{ng} / \mathrm{dL}$.

Statistical analysis was performed using SPSS software version 15.0 for Windows. Pearson's Chi-square test was used for comparison between non-numerical variables, while t-test and ANOVA was used for comparison between numeric variables. A p value of 0.05 was considered the cut off for statistical significance.

\section{RESULTS}

Of the total number of 5315 patients evaluated in this urological examination program from January to December 2011, 300 were excluded due to any one of the exclusion criteria lis- 
ted above. Thus, a total of 5015 men with an average age of $49.0+/-4.0$ years completed the study. Out of 5015 men, 3880 (77.3\%) were white and only 90 $(1.7 \%)$ were black. The overall prevalence of diabetes mellitus in our population was 3.9\% (197/5015). These demographic data are presented in Table-1.

The average PSA was less than $2.5 \mathrm{ng} / \mathrm{mL}$ for all age groups. Older men had higher values of PSA, prostate size and IPSS score.Table-2 presents the averages of PSA, IPSS and prostate size of the 5015 men.

Further analysis was performed in order to correlate different PSA cutoffs with aging, IPSS, and prostate size. The first cutoff was $2.5 \mathrm{ng} / \mathrm{mL}$. Out of 5015 men included in this study, 4723 (94.17\%) had PSA less than $2.5 \mathrm{ng} / \mathrm{mL}, 192$ (3.8\%) had PSA between 2.5 and $4.0 \mathrm{ng} / \mathrm{mL}$, and 100 (1.9\%) had PSA greater than $4.0 \mathrm{ng} / \mathrm{mL}$. The prevalence of PSA $>2.5 \mathrm{ng} / \mathrm{mL}$ was higher in older men. Higher PSA levels correlated with higher IPSS and larger prostate size. These data are presented in Table-3.

A total of 192 men had PSA between 2.5 and $4 \mathrm{ng} / \mathrm{mL}$. Among these men 130 were submitted to prostate biopsy. The predictive positive value of prostate biopsy was 25\% (32/130).

Table 1 - Demographic data of 5015 men.

\begin{tabular}{lcccc}
\hline & $40-49$ years & $50-59$ years & $60-70$ years & $p$ \\
\hline $\mathrm{N}$ & $2813(56 \%)$ & $1726(34.5 \%)$ & $476(9.5 \%)$ & 0.001 \\
Race & & & \\
\\
White & $2700(95.1 \%)$ & $1650(95.5 \%)$ & $430(90.3 \%)$ & 0.01 \\
Black & $50(1.7 \%)$ & $30(1.8 \%)$ & $10(2.2 \%)$ & 0.02 \\
Others & $63(2.2 \%)$ & $46(2.7 \%)$ & $36(7.5 \%)$ & 0.04 \\
Smoking & $279(9.9 \%)$ & $189(10.9 \%)$ & $35(7.3 \%)$ & 0.03 \\
Diabetes & $54(1.9 \%)$ & $89(5.1 \%)$ & $54(11.3 \%)$ & 0.01 \\
BMI $\left(\mathrm{Kg} / \mathrm{m}^{2}\right)$ & $27.04 \pm 4.9$ & $27.6 \pm 4.5$ & $27.4 \pm 5.3$ & 0.59 \\
\hline
\end{tabular}

BMI: Body Mass Index

Table 2 - Averages of total PSA, IPSS and Prostate size of the $\mathbf{5 0 1 5}$ men.

\begin{tabular}{lcccc}
\hline & $40-49$ years & $50-59$ years & $60-70$ years & $p$ \\
\hline Men & $2813(56 \%)$ & $1726(34.5 \%)$ & $476(9.5 \%)$ & 0.01 \\
Total PSA (ng/dL) & $0.9 \pm 0.7$ & $1.2 \pm 0.5$ & $1.7 \pm 1.5$ & 0.01 \\
IPSS $\leq 7$ & $2797(99.4 \%)$ & $1642(95.1 \%)$ & $381(80 \%)$ & 0.03 \\
IPSS $>7$ & $16(0.6 \%)$ & $84(4.9 \%)$ & $95(20 \%)$ & 0.03 \\
Prostate Size (grams) & $25.2 \pm 7.3$ & $30.9 \pm 11.2$ & $38 \pm 18.8$ & 0.03 \\
Suspicious DRE & $17 / 2813$ & $63 / 1726$ & $50 / 476$ & 0.02 \\
\hline
\end{tabular}

IPSS: International Prostate Symptom Score; DRE: Digital Rectal Examination 
Table 3 - Prevalence of PSA less than 2.5, PSA between 2.5 and 4.0, and PSA greater than 4.0ng/dL in the different aging groups.

\begin{tabular}{|c|c|c|c|c|}
\hline & $P S A<2.5 \mathrm{ng} / \mathrm{dL}$ & PSA 2.5 to $4.0 \mathrm{ng} / \mathrm{dL}$ & $\mathrm{PSA}>4.0 \mathrm{ng} / \mathrm{dL}$ & $p$ \\
\hline \multicolumn{5}{|l|}{ Age } \\
\hline $40-49$ years & $2763(98.2 \%)$ & $35(1.2 \%)$ & $15(0.6 \%)$ & 0.01 \\
\hline $50-59$ years & $1575(91.2 \%)$ & $108(6.2 \%)$ & $43(2.6 \%)$ & 0.03 \\
\hline $60-70$ years & $385(80.8 \%)$ & $49(10.2 \%)$ & $42(9 \%)$ & 0.04 \\
\hline \multicolumn{5}{|l|}{ IPSS } \\
\hline $40-49$ years & $0.37 \pm 0.1$ & $0.6 \pm 0.2$ & $0.78 \pm 0.4$ & 0.01 \\
\hline $50-59$ years & $1.01 \pm 0.3$ & $1.6 \pm 0.5$ & $2.4 \pm 0.9$ & 0.01 \\
\hline $60-70$ years & $2.5 \pm 0.7$ & $2.4 \pm 0.9$ & $4.6 \pm 1.9$ & 0.01 \\
\hline \multicolumn{5}{|l|}{ Prostate Size } \\
\hline $40-49$ years & $25 \pm 2.3$ & $27 \pm 4$ & $29 \pm 7$ & 0.01 \\
\hline $50-59$ years & $28 \pm 3$ & $30.2 \pm 5$ & $35 \pm 3$ & 0.01 \\
\hline $60-70$ years & $32.5 \pm 2$ & $38.5 \pm 5$ & $43.7 \pm 7$ & 0.01 \\
\hline \multicolumn{5}{|l|}{ Free PSA ng/dL } \\
\hline 40-49 years & & $0.54 \pm 0.2$ & $0.69 \pm 0.2$ & 0.03 \\
\hline $50-59$ years & & $0.62 \pm 0.15$ & $0.77 \pm 0.3$ & 0.01 \\
\hline $60-70$ years & & $0.79 \pm 0.4$ & $0.83 \pm 0.5$ & 0.05 \\
\hline
\end{tabular}

The Gleason score was 6 in 24 men (75\%), and 7 in 8 men (25\%). In the same way, 100 patients had PSA $\geq 4 \mathrm{ng} / \mathrm{mL}$. From these men, 80 were submitted to prostate biopsy. In this group, the predictive positive value of prostate biopsy was 40\% (32/100). The Gleason score was 6 in 19 men (60\%), 7 in 10 men (31\%) and 8 in 3 men (9\%). Regarding the treatment option of each patient, we do not have the follow-up. These data are presented in Table- 4 .

The second cutoff point used for statistical analysis was $1.5 \mathrm{ng} / \mathrm{mL}$. Out of 5015 men, 3978 (79.3\%) had PSA less than $1.5 \mathrm{ng} / \mathrm{mL}$. As well as for $2.5 \mathrm{ng} / \mathrm{mL}$ cutoff, the prevalence of PSA > $1.5 \mathrm{ng} / \mathrm{mL}$ also increased with age, and was quite similar in men between the ages of 50 and 59, and greater than 60 years of age $(38.6 \%$ and 36\% respectively). These data are presented in Table-5.

\section{DISCUSSION}

The primary objective of this study was to evaluate the PSA levels in a large population of young Brazilian men submitted to a health check-up program. The second objective was to correlate the different PSA cutoff with age, prostate size, and urinary symptoms. The data was collected in Sao Paulo, Brazil, from one of the largest check up program ever performed in a private hospital. This study was obtained from a database of 5015 men between the ages of 40 and 70, with an average age of 49 years old. Most of the 
subjects were white, non-smokers, without co-morbidities such as diabetes, and have no urological complaints. The averages of total PSA in the three different aging groups were $0.9 \mathrm{ng} / \mathrm{mL}$ for men between the ages of 40 and $50 ; 1.2 \mathrm{ng} /$
$\mathrm{mL}$ for men between 50 and 60 ; and $1.7 \mathrm{ng} / \mathrm{mL}$ for men greater than 60 years old. Out of 5015 men, $4820(96.11 \%)$ had an IPSS less or equal to 7. The prevalence of PSA greater than $2.5 \mathrm{ng} /$ $\mathrm{mL}$ was $1.8 \%$ in men between the ages of 40 and

Table 4 - The prevalence of PSA greater or less than $1.5 \mathrm{ng} / \mathrm{dL}$ and its correlation with IPSS and prostate size.

\begin{tabular}{lcccc}
\hline & $40-49$ years & $50-59$ years & $60-70$ years & $p$ \\
\hline $\mathbf{N}$ & 2813 & 1726 & 476 & \\
PSA $<1.5 \mathrm{ng} / \mathrm{dL}$ & $2612(92.8)$ & $1061(62.4 \%)$ & $305(64 \%)$ & 0.02 \\
PSA $>1.5 \mathrm{ng} / \mathrm{dL}$ & $201(7.2 \%)$ & $665(38.6 \%)$ & $171(36 \%)$ & 0.02 \\
Avg IPSS & & & & 0.03 \\
$\quad$ PSA $<1.5 \mathrm{ng} / \mathrm{dL}$ & $0.33 \pm 0.1$ & $0.95 \pm 0.4$ & $2.5 \pm 1.3$ & 0.03 \\
$\quad$ PSA $>1.5 \mathrm{ng} / \mathrm{dL}$ & $0.64 \pm 0.2$ & $1.6 \pm 0.7$ & $3.8 \pm 1.7$ & \\
Avg Prostate Size & & & $30 \pm 7$ & 0.02 \\
PSA $<1.5 \mathrm{ng} / \mathrm{dL}$ \\
PSA $>1.5 \mathrm{ng} / \mathrm{dL}$
\end{tabular}

Avg: Average; IPSS: International Prostate Symptom Score

Table 5 - The prevalence of PSA greater or less than $1.5 \mathrm{ng} / \mathrm{dL}$ and its correlation with IPSS and prostate size.

\begin{tabular}{|c|c|c|c|}
\hline & $\mathrm{PSA}<1.5 \mathrm{ng} / \mathrm{dL}$ & $\mathrm{PSA}>1.5 \mathrm{ng} / \mathrm{dL}$ & $p$ \\
\hline \multicolumn{4}{|l|}{ Age } \\
\hline $40-49$ years & $2612(92.8 \%)$ & $201(7.2 \%)$ & 0.02 \\
\hline $50-59$ years & $1061(62,4 \%)$ & $665(38.6 \%)$ & 0.02 \\
\hline $60-70$ years & $305(64 \%)$ & $171(36 \%)$ & 0.02 \\
\hline \multicolumn{4}{|l|}{ IPSS } \\
\hline $40-49$ years & $0.33 \pm 0.1$ & $0.64 \pm 0.2$ & 0.03 \\
\hline $50-59$ years & $0.95 \pm 0.4$ & $1.6 \pm 0.7$ & 0.03 \\
\hline $60-70$ years & $2.5 \pm 1.3$ & $3.8 \pm 1.7$ & 0.03 \\
\hline \multicolumn{4}{|c|}{ Prostate Size (grams) } \\
\hline $40-49$ years & $23.3 \pm 3$ & $27 \pm 8$ & 0.01 \\
\hline $50-59$ years & $30.1 \pm 5$ & $33 \pm 7$ & 0.02 \\
\hline $60-70$ years & $30 \pm 7$ & $35.9 \pm 9$ & 0.01 \\
\hline
\end{tabular}


50; 8.8\% between 50 and 60; and 11.1\% after 60 years of age. Only $20.6 \%$ had a PSA level greater than $1.5 \mathrm{ng} / \mathrm{mL}$. The predictive positive value of prostate biopsy in men with PSA between 2.5 to $4 \mathrm{ng} / \mathrm{mL}$ was $25 \%$ and all of them had Gleason score $\leq 7$. In the same way, the predictive positive value of prostate biopsy in men with PSA $\geq$ $4 \mathrm{ng} / \mathrm{mL}$ was $40 \%$ and $91 \%$ of them had Gleason score $\leq 7$.

The primary goal of prostate cancer screening in this specific population of younger men is the early detection of prostate cancer. Regarding prostate screening programs, men can potentially fall into 1 of 3 categories: 1) those whose cancer will result in death despite early diagnosis and treatment; 2) those who will have good outcomes in the absence of screening; and 3) those for whom early diagnosis and treatment improve survival.

There is convincing evidence that with or without screening the number of men who survive prostate cancer after 10 to 14 years is, at best, very small $(14,15)$. In addition, the inevitability of overdiagnosis and overtreatment of prostate cancer as a result of screening means that many men will experience the adverse effects of diagnosis and treatment of a disease that would have remained asymptomatic throughout their lifetime. In accordance with the U.S. Preventive Services Task Force (USPSTF) statement of recommendations published in 2012, there is moderate certainty that the benefits of PSA-based screening for prostate cancer do not outweigh its harmful effects (3).

False positive PSA test results are common and vary depending on the PSA cutoff and frequency of screening. After four PSA tests, men in the screening group of the PLCO trial had a $12.9 \%$ cumulative risk for at least 1 false positive result, and a 5.5\% risk for at least 1 biopsy due to a false positive result. A false positive result has a negative impact on patient's quality of life $(4,14)$. The ProtecT study found that $32 \%$ of men submitted to a prostate biopsy experienced pain; fever; blood in the urine, semen, or stool; infection; transient urinary difficulties; or other issues that they considered a moderate or major problem (9).
In the present study, the majority of men was white and less than 50 years old. According to recent data, the recommendation of PSA screening in this specific population remains controversial. It is well established that age, race, and family history of prostate cancer increase the risk of developing and dying of the disease. Black men are approximately twice as likely to die of prostate cancer than other men, and the reason for this disparity is unknown (16). Preliminary results from PIVOT (Prostate Cancer Intervention Versus Observation Trial), in which 30\% of enrollees were black, found no difference in outcomes due to treatment of prostate cancer in these men compared with other races (17). Despite controversies, the 2013 American Urological Association Guidelines recognized that the PSA screening test might benefit certain subgroups of younger men with high risk of prostate cancer. However, this report suggests that patients should be informed about the potential harmful effects of these tests as well as the benefits of screening at an earlier age. Physicians should be aware that there are no comparative data and the best approach for this specific group is not well established (18).

The PSA-based screening in men 50 to 74 years of age has been evaluated in 5 randomized, controlled trials with different cutoffs and screening intervals. The PLCO trial found a nonstatistically significant increase in prostate cancer mortality in the annual screening group at 11.5 and 13 years post diagnosis $(4,14)$. The ERSPC trial demonstrated a mortality ratio (RR) of 0.80 (95\% CI, 0.65 to 0.98) in screened men after a median follow up of 9 years, with similar findings at 11 years (RR 0.79, CI 0.68 to 0.91$)(5,15)$. In the present study $2080(41.4 \%)$ men were older than 50 years of age, 4723 (94.17\%) had PSA less than 2.5ng/dL, and 3978 (79.3\%) had PSA less than $1.5 \mathrm{ng} / \mathrm{dL}$.

In a prevalence study and clinical significance of prostate cancer among 12682 men with normal DRE and low PSA levels Pepe et al. have shown that $27.4 \%$ of men with PSA between 2.5 and $4 \mathrm{ng} / \mathrm{mL}$ had prostate cancer and some of them were clinically significant (19). Another recent study published by Faria et al. evaluated the 
detection rates, clinical and pathological findings in Brazilian men with serum PSA levels $<4 n g$ / $\mathrm{mL}$. In this study the predictive positive value of prostate biopsy in men with PSA between 2.5 and $3.9 \mathrm{ng} / \mathrm{mL}$ was $31.1 \%$. All patients had clinical stage I and 96.8\% had Gleason score $\leq 7$. After radical prostatectomy, $82.4 \%$ had pathological stage T2 and $17.6 \%$ had pathological stage T3 (20). In our study we have found similar results regarding prostate biopsy predictive positive value. For patients with PSA between 2.5 and $3.9 \mathrm{ng} / \mathrm{mL}, 25 \%$ had prostate cancer and all of them had Gleason score $\leq 7$. On the other hand, the predictive positive value of prostate biopsy in patients with PSA $\geq 4 \mathrm{ng} / \mathrm{mL}$ was $40 \%$ and $9 \%$ had Gleason score $>7$.

The conventional PSA cutoff of $4.0 \mathrm{ng} / \mathrm{dL}$ detects most cases of prostate cancer; however, some cases will be missed. Using a lower cutoff point detects more cases of cancer but at the cost of labeling more men as potentially having the disease. When the PSA cutoff decreases to $2.5 \mathrm{ng} / \mathrm{dL}$ more than double the number of men aged 40 to 69, with abnormal results, show a false positive result. This cutoff level also increases the likelihood of detection of indolent tumors with no clinical importance. Conversely, increasing the PSA cutoff to a level greater than 10ng/ $\mathrm{dL}$ would reduce a prostate cancer diagnosis in the number of men aged 50 to 69 with abnormal results from 1.2 million to roughly 352,000 . It is important to note there is no PSA cutoff at which a man can be guaranteed to be free from prostate cancer $(21,22)$.

Despite the benefits of this large population sample of Brazilian men who underwent this urological examination, the limitations of this study must be recognized. First, it was performed with patients referred to a private hospital, who have a good health insurance and a better medical care whether compared to the whole Brazilian population. Second, our database did not have patient family history information. Third, 60 cases with PSA between 2.5 and 2.9ng/ $\mathrm{dL}$, and 20 cases with PSA > 4.0ng/dL were not submitted to prostate biopsies. This precludes accurate conclusions regarding prostate cancer incidence in this population.
The idea of prostate screening implies that most asymptomatic prostate cancers could become clinically important and lead to poor health outcomes, and that early treatment could effectively reduce prostate cancer specifically and thereby reduce mortality rates overall. However, long-term, population based cohort studies, and randomized treatment trials of conservatively managed men with localized prostate cancer do not support this hypothesis (6).

Our database showed that the PSA level in Brazilian men submitted to a health check-up program was low. In this context, it should be emphasized that lower PSA levels do not exclude prostate cancer. According to some population-based studies, approximately 25\% of men with PSA $<4.0 n g / d L$ will have prostate cancer with Gleason score higher than 6 .

The PSA level had a positive correlation with age, prostate size and prostate symptoms. Despite some of the limitations, we believe that this study provides substantial information about PSA screening tests performed in younger men from underdeveloped countries. To our knowledge this study represents the first urological Brazilian-database report carried out with this large number of patients.

\section{ACKNOWLEDGEMENTS}

Christina Ross, who participate on the manuscript elaboration and english grammar review.

\section{CONFLICT OF INTEREST}

None declared.

\section{REFERENCES}

1. Jemal A, Bray F, Center MM, Ferlay J, Ward E, Forman D. Global cancer statistics. CA Cancer J Clin. 2011;61:69-90. Erratum in: CA Cancer J Clin. 2011;61:134.

2. Ilic D, O'Connor D, Green S, Wilt TJ. Screening for prostate cancer: an updated Cochrane systematic review. BJU Int. 2011; 107: 882-91.

3. Ilic D, O'Connor D, Green S, Wilt T. Screening for prostate cancer. Cochrane Database Syst Rev. 2006;19:(3):CD004720. Review. Update in: Cochrane Database Syst Rev. 2013:1:CD004720. 
4. Andriole GL, Crawford ED, Grubb RL 3rd, Buys SS, Chia D, Church TR, et al. Mortality results from a randomized prostate-cancer screening trial. N Engl J Med. 2009; 360: 1310-9. Erratum in: N Engl J Med. 2009;360:1797.

5. Schröder FH, Hugosson J, Roobol MJ, Tammela TL, Ciatto $\mathrm{S}$, Nelen V, et al. Screening and prostate-cancer mortality in a randomized European study. N Engl J Med. 2009; 360: 1320-8.

6. Moyer VA; U.S. Preventive Services Task Force: Screening for prostate cancer: U.S. Preventive Services Task Force recommendation statement. Ann Intern Med. 2012; 157: 120-34.

7. Welch HG, Schwartz LM, Woloshin S. Prostate-specific antigen levels in the United States: implications of various definitions for abnormal. J Natl Cancer Inst. 2005;97:1132-7.

8. Lin K, Lipsitz R, Miller T, Janakiraman S; U.S. Preventive Services Task Force: Benefits and harms of prostate-specific antigen screening for prostate cancer: an evidence update for the U.S. Preventive Services Task Force. Ann Intern Med. 2008; 149: 192-9.

9. Rosario DJ, Lane JA, Metcalfe C, Donovan JL, Doble A, Goodwin L, et al. Short term outcomes of prostate biopsy in men tested for cancer by prostate specific antigen: prospective evaluation within ProtecT study. BMJ. 2012; 344: d7894.

10. Scosyrev E, Wu G, Golijanin D, Messing E. Prostate-specific antigen testing in older men in the USA: data from the behavioral risk factor surveillance system. BJU Int. 2012; 110: 1485-90.

11. Welch HG, Albertsen PC. Prostate cancer diagnosis and treatment after the introduction of prostate-specific antigen screening: 1986-2005. J Natl Cancer Inst. 2009; 101: 1325-9.

12. Ganz PA, Barry JM, Burke W, Col NF, Corso PS, Dodson $E$, et al. National Institutes of Health State-of-the-Science Conference: role of active surveillance in the management of men with localized prostate cancer. Ann Intern Med. 2012; 156: $591-5$.

13. Bosch JL, Hop WC, Kirkels WJ, Schröder FH. The International Prostate Symptom Score in a communitybased sample of men between 55 and 74 years of age: prevalence and correlation of symptoms with age, prostate volume, flow rate and residual urine volume. Br J Urol. 1995; 75: 622-30.

14. Andriole GL, Crawford ED, Grubb RL 3rd, Buys SS, Chia D, Church TR, Fouad MN, et al. Prostate cancer screening in the randomized Prostate, Lung, Colorectal, and Ovarian Cancer Screening Trial: mortality results after 13 years of follow-up. J Natl Cancer Inst. 2012; 104: 125-32.
15. Schröder FH, Hugosson J, Roobol MJ, Tammela TL, Ciatto $\mathrm{S}$, Nelen V, et al. Prostate-cancer mortality at 11 years of follow-up. N Engl J Med. 2012; 366: 981-90. Erratum in: N Engl J Med. 2012;366:2137.

16. Howlader N, Noone AM, Krapcho M, Neyman N, Aminou $\mathrm{R}$, Waldron W, et al, eds. SEER Cancer Statistics Review, 1975-2008. Bethesda, MD: National Cancer Institute 2011; Acessed as http://seer.cancer.gov/csr/1975_2008/index. html.

17. Wilt TJ: The Prostate Cancer Intervention Versus Observation Trial: VA/NCI/AHRQ Cooperative Studies Program \#407 (PIVOT): design and baseline results of a randomized controlled trial comparing radical prostatectomy with watchful waiting for men with clinically localized prostate cancer. J Natl Cancer Inst Monogr. 2012; 2012: 184-90.

18. Brawley OW. Prostate cancer epidemiology in the United States. World J Urol. 2012; 30: 195-200.

19. Pepe $P$, Panella P, Savoca F, Cacciola A, D'Arrigo L, Dibenedetto $G$, et al. Prevalence and clinical significance of prostate cancer among 12,682 men with normal digital rectal examination, low PSA levels $(<0 \mathrm{r}=4 \mathrm{ng} / \mathrm{ml}$ ) and percent free PSA cutoff values of 15 and 20\%. Urol Int. 2007; 78: 308-12.

20. Faria EF, Carvalhal GF, Reis RB, Tobias-Machado MT, Vieira RAC, Reis LO, Nogueira L, et I. Use of low free to total PSA ratio in prostate cancr screening: detection rates, clinical and pathological findings in Brazilian men with serum PSA levels $<4.0$ ng/ml. BJUlnt. 2012; 110(11 Pt B): E653-E657.

21. Welch HG, Schwartz LM, Woloshin S: Prostate-specific antigen levels in the United States: implications of various definitions for abnormal. J Natl Cancer Inst. 2005; 97: 1132-7.

22. Thompson IM, Ankerst DP, Chi C, Lucia MS, Goodman PJ Crowley JJ, et al.: Operating characteristics of prostatespecific antigen in men with an initial PSA level of $3.0 \mathrm{ng} / \mathrm{ml}$ or lower. JAMA. 2005; 294: 66-70. 